Connecticut College

Digital Commons @ Connecticut College

1871

\title{
There is a Green Hill Far Away
}

Charles Gounod

Mrs. Cecil Francis Alexander

Follow this and additional works at: https://digitalcommons.conncoll.edu/sheetmusic

\section{Recommended Citation}

Gounod, Charles and Alexander, Mrs. Cecil Francis, "There is a Green Hill Far Away" (1871). Historic Sheet Music Collection. 1084.

https://digitalcommons.conncoll.edu/sheetmusic/1084

This Score is brought to you for free and open access by the Greer Music Library at Digital Commons @ Connecticut College. It has been accepted for inclusion in Historic Sheet Music Collection by an authorized administrator of Digital Commons @ Connecticut College. For more information, please contact bpancier@conncoll.edu.

The views expressed in this paper are solely those of the author. 


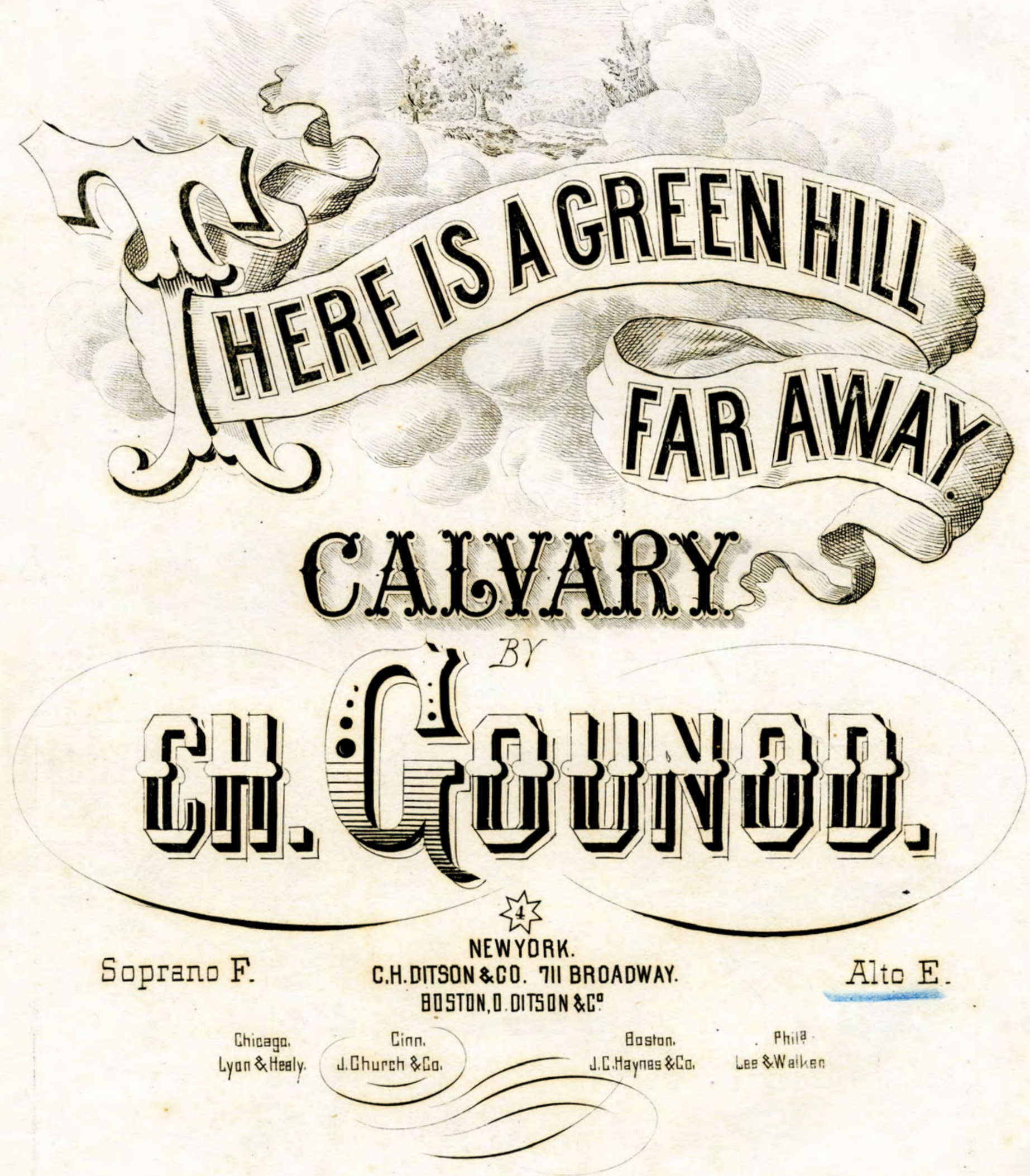




\section{D.H. 月.}

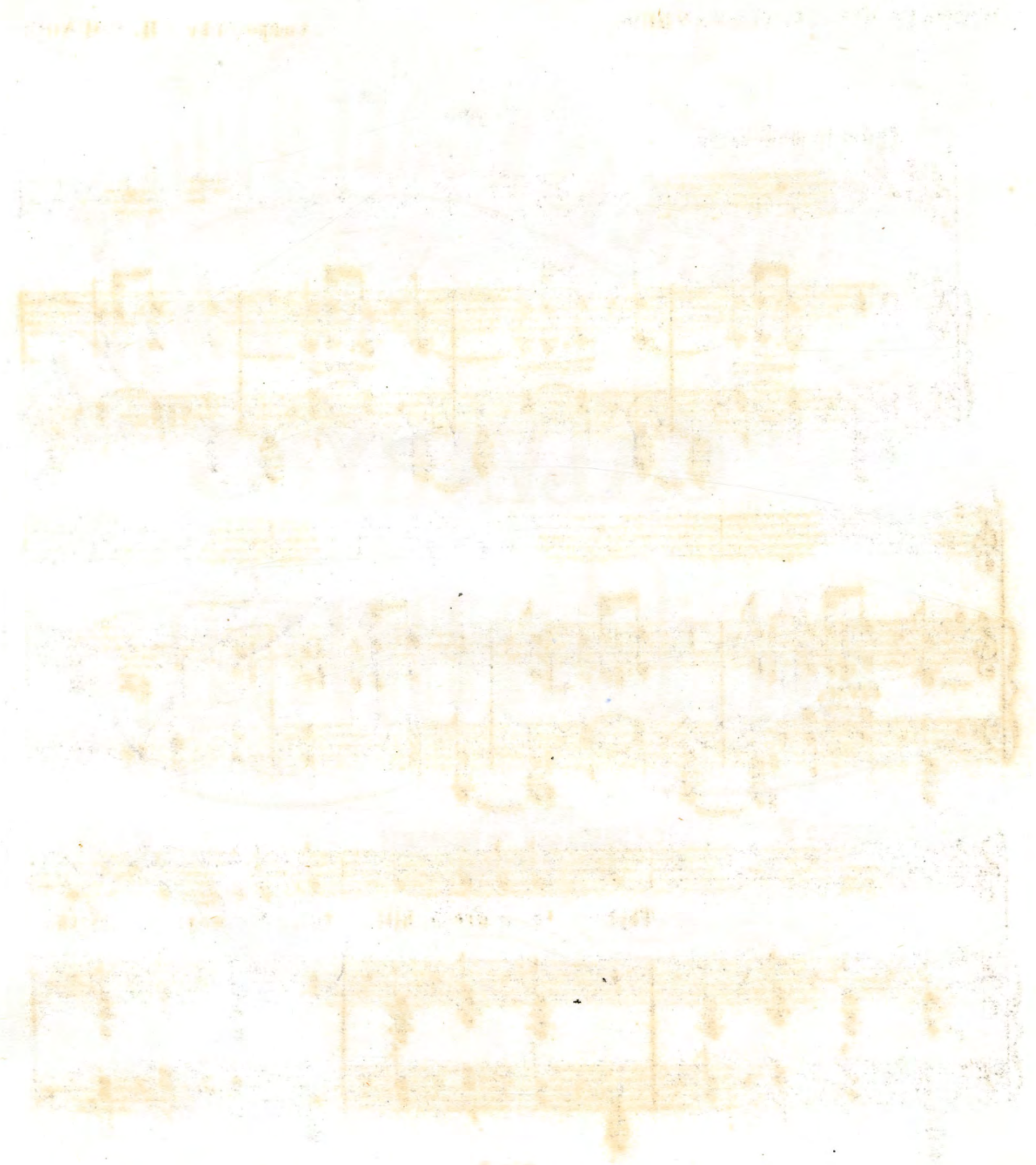

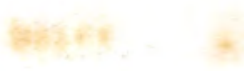

P 


\section{THERE IS A GREEN HILL FAR AWAY.}

Written by Mrs C. F. ALEXANDER.

Composed by CH. GOUNOD.

$A$ L TO.

E minor\& major.
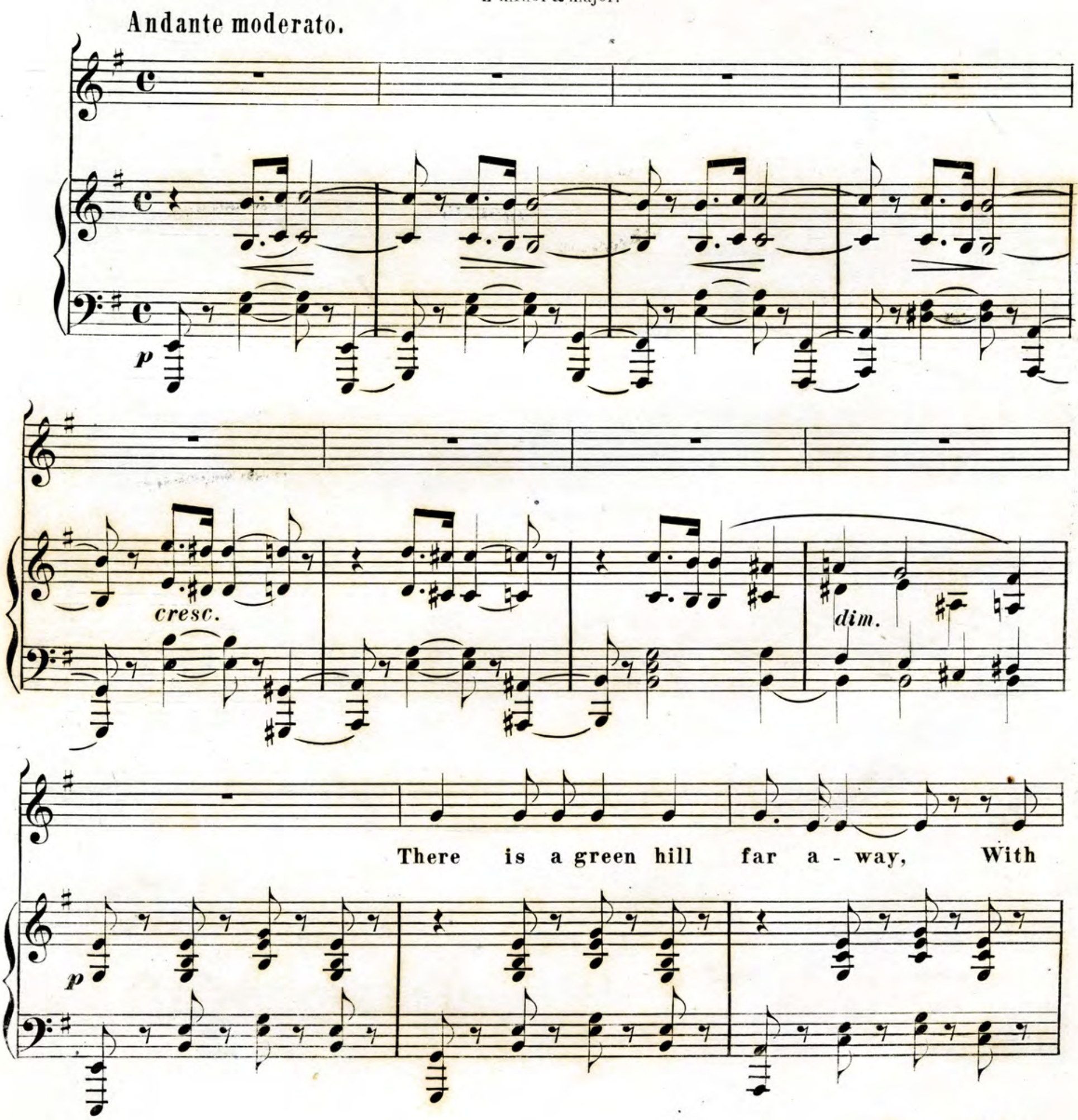

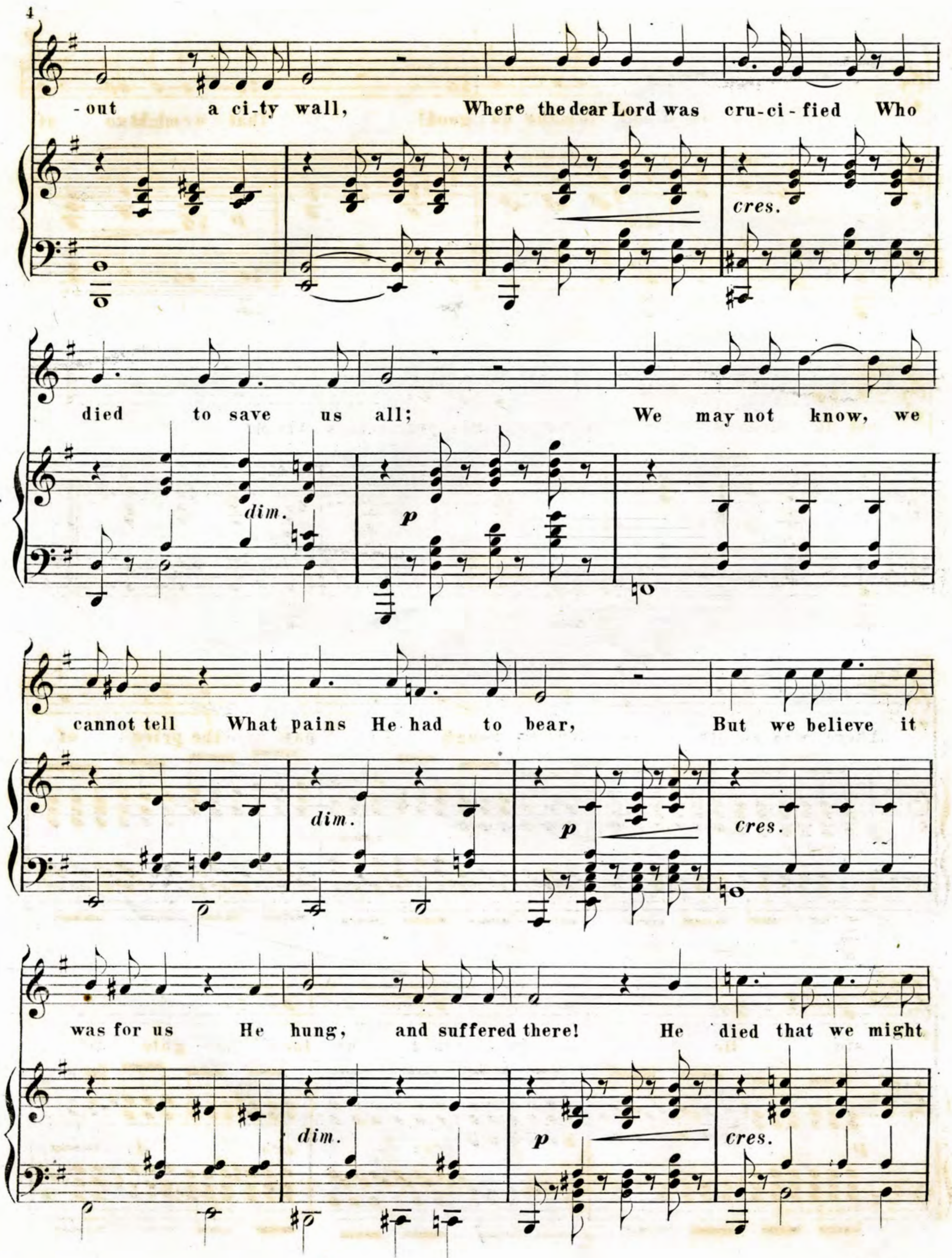

46486 

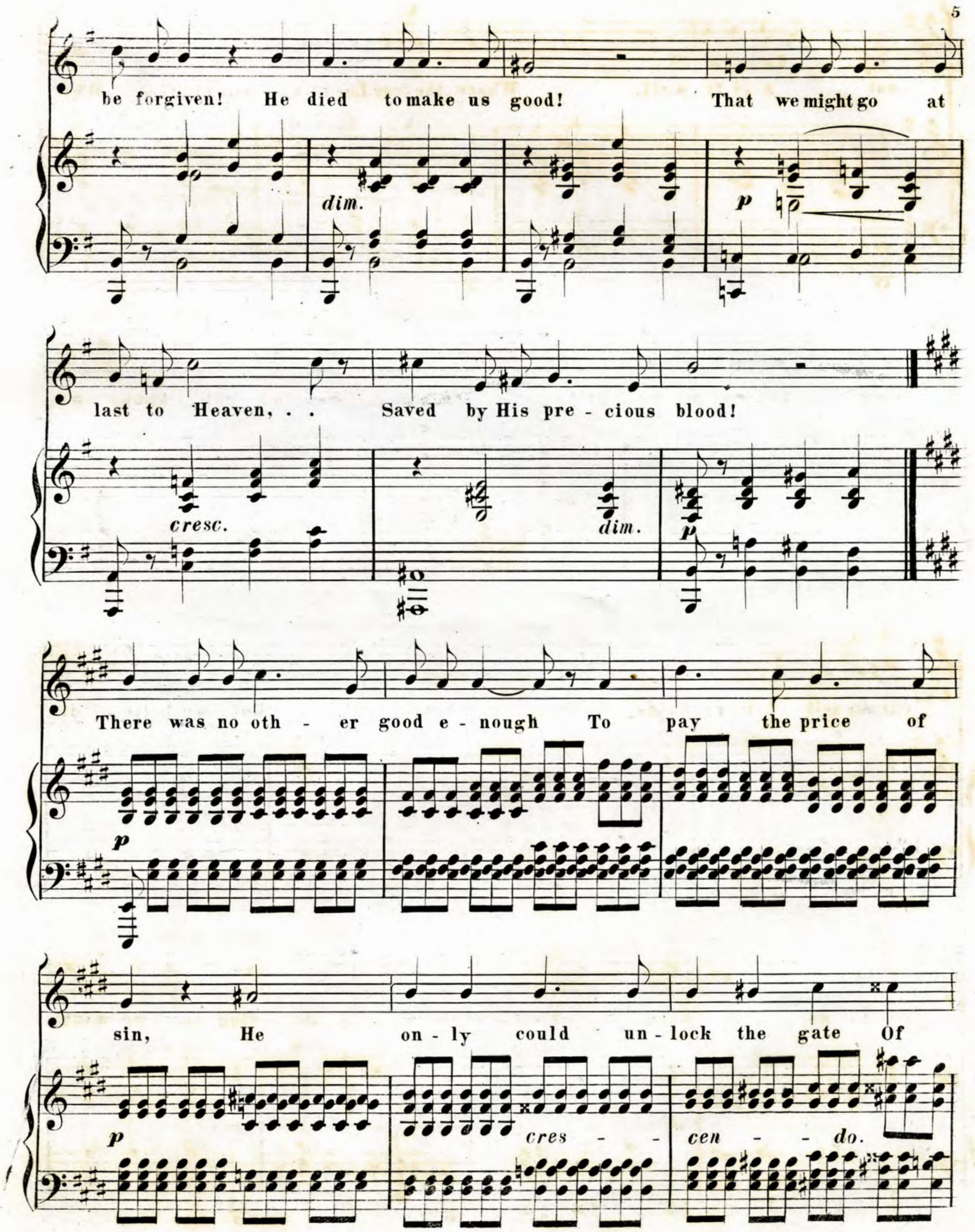


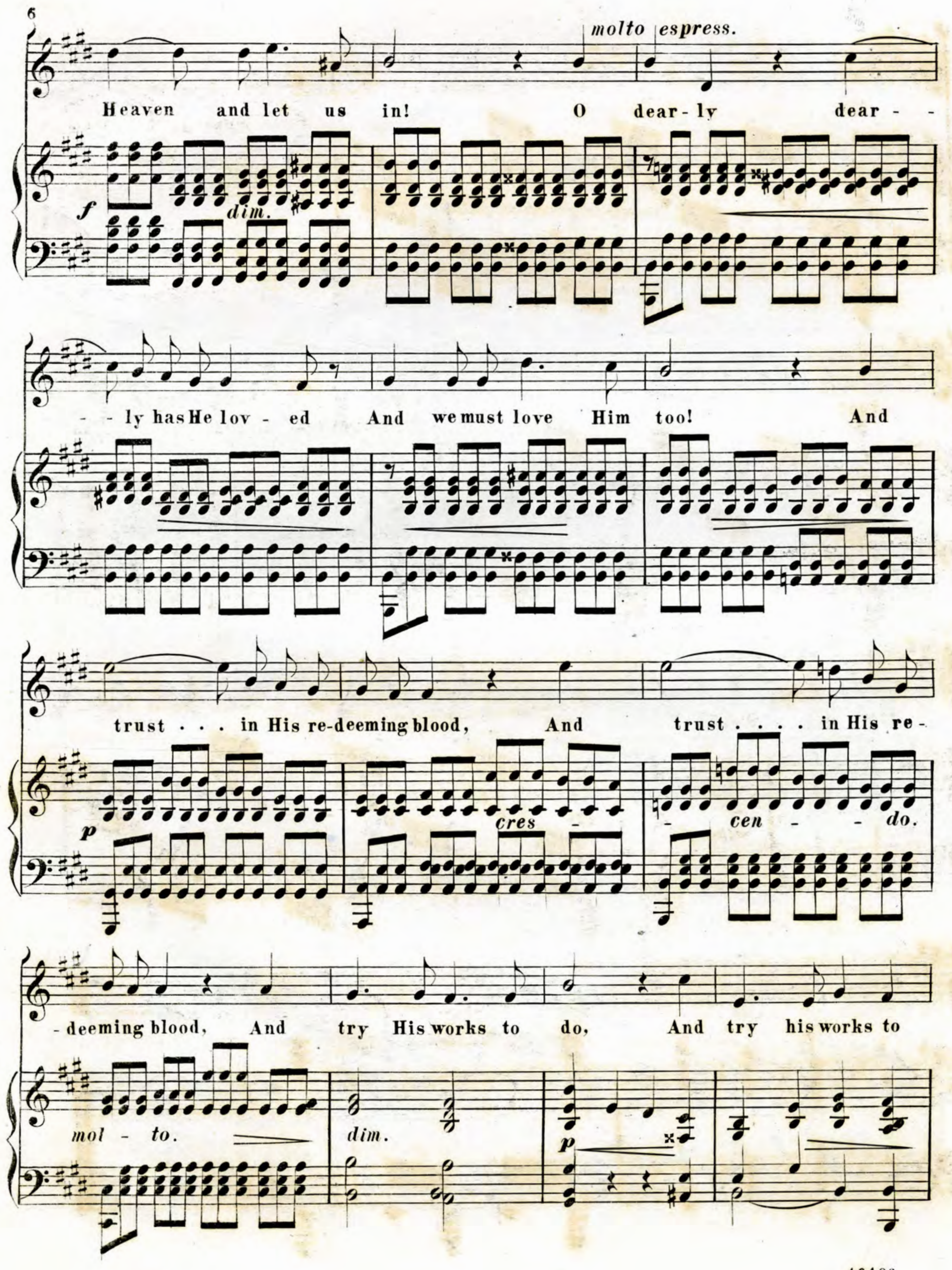



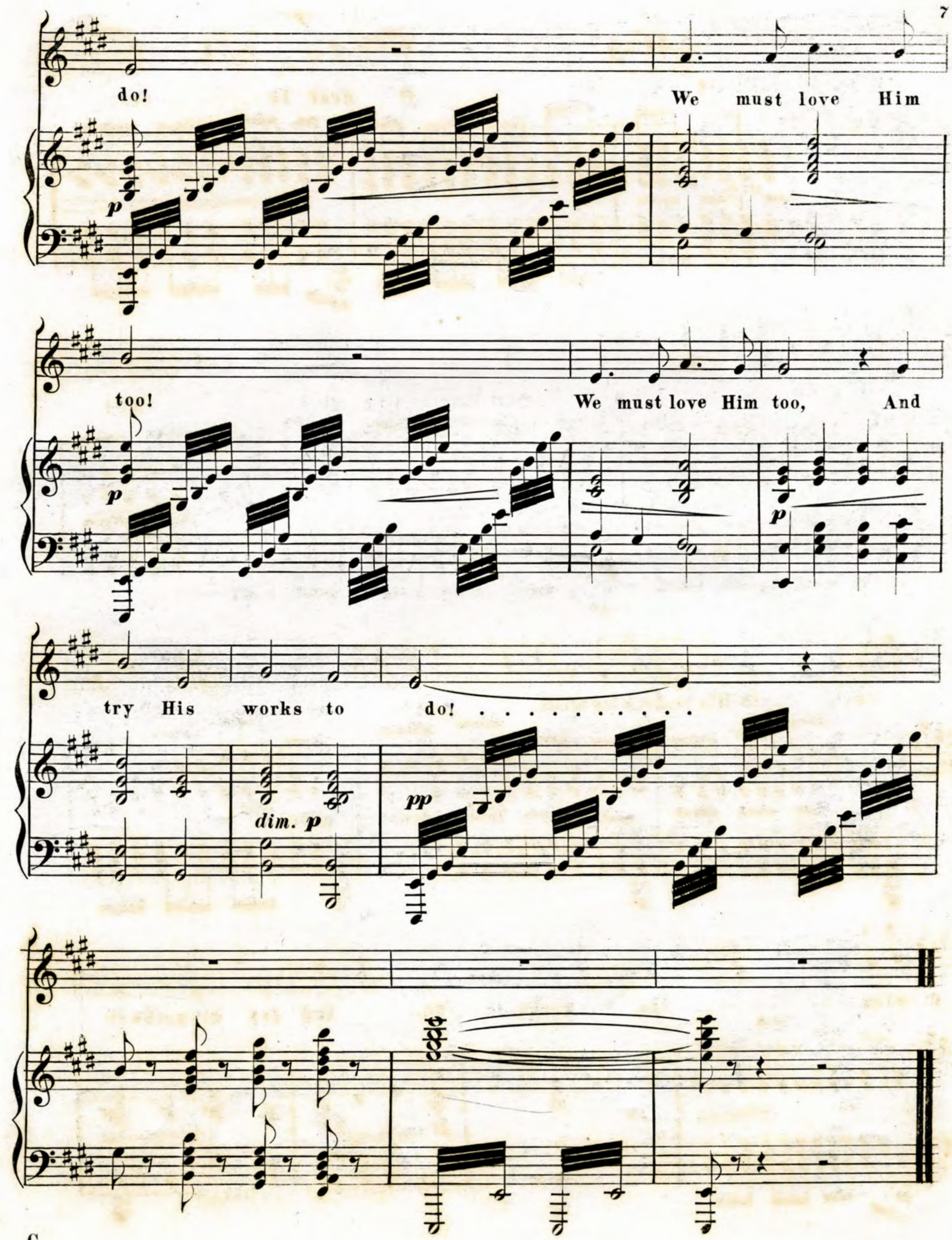

G. 
a

$\therefore$

xa

.

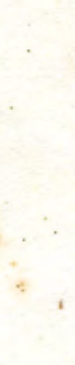

.

.

nan

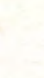

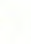

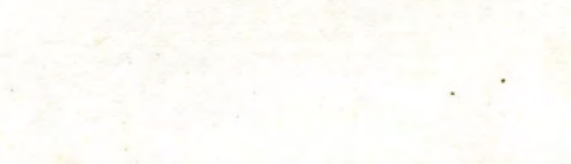

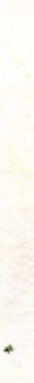

.

n

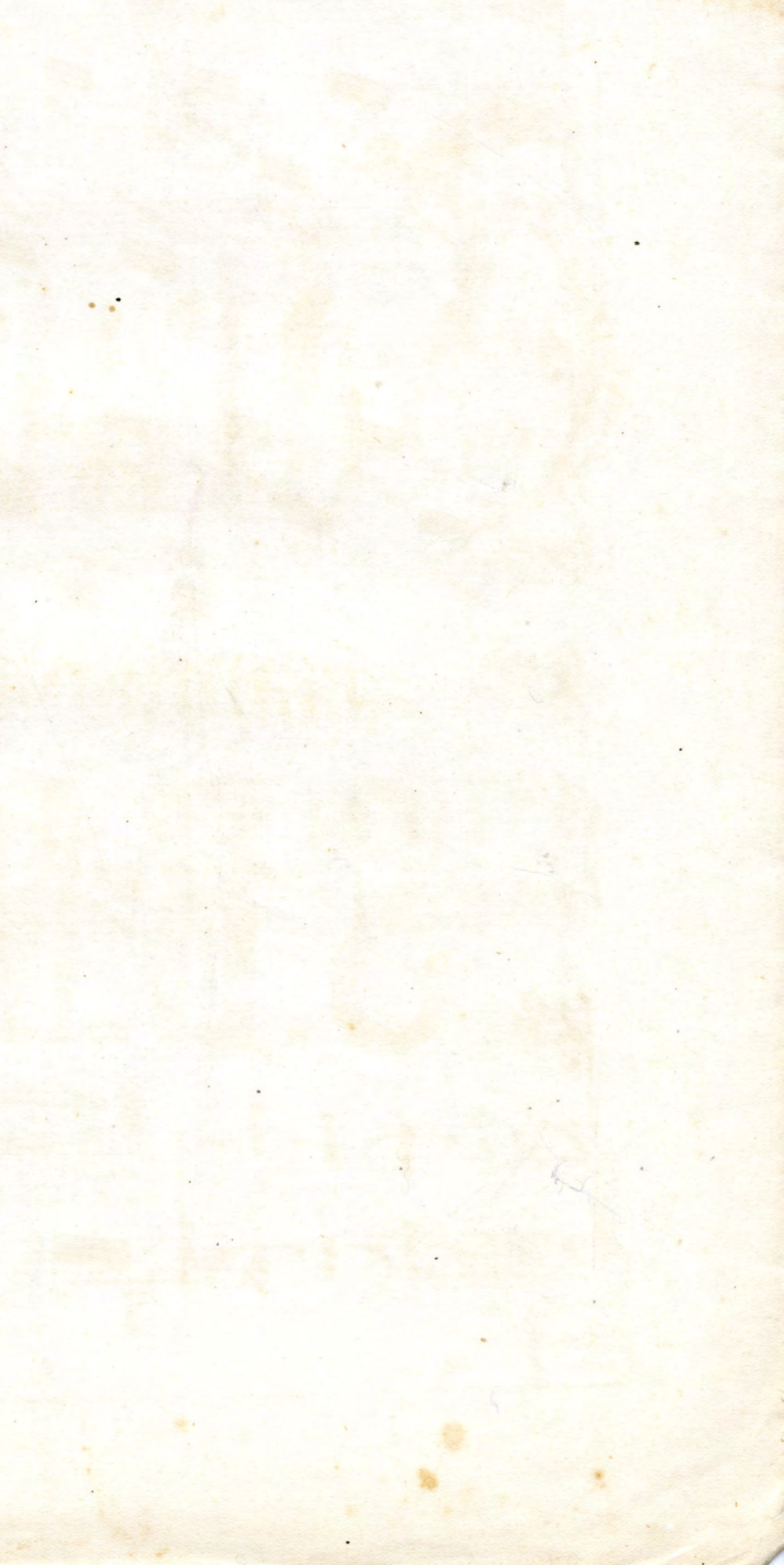

$\therefore$ 